\title{
The Balance of Striatal Feedback Transmission Is Disrupted in a Model of Parkinsonism
}

\author{
Violeta G. López-Huerta, Luis Carrillo-Reid, Elvira Galarraga, Dagoberto Tapia, Tatiana Fiordelisio, \\ Rene Drucker-Colin, and Jose Bargas \\ División de Neurociencias, Instituto de Fisiología Celular, Universidad Nacional Autónoma de México, México City, DF 04510 México
}

Inhibitory connections among striatal projection neurons (SPNs) called "feedback inhibition," have been proposed to endow the striatal microcircuit with computational capabilities, such as motor sequence selection, filtering, and the emergence of alternating network states. These properties are disrupted in models of Parkinsonism. However, the impact of feedback inhibition in the striatal network has remained under debate. Here, we test this inhibition at the microcircuit level. We used optical and electrophysiological recordings in mice and rats to demonstrate the action of striatal feedback transmission in normal and pathological conditions. Dynamic calcium imaging with single-cell resolution revealed the synchronous activation of a pool of identified SPNs by antidromic stimulation. Using bacterial artificial chromosome-transgenic mice, we demonstrate that the activated neuron pool equally possessed cells from the direct and indirect basal ganglia pathways. This pool inhibits itself because of its own GABA release when stimuli are frequent enough, demonstrating functional and significant inhibition. Blockade of $\mathrm{GABA}_{\mathrm{A}}$ receptors doubled the number of responsive neurons to the same stimulus, revealing a second postsynaptic neuron pool whose firing was being arrested by the first pool. Stronger connections arise from indirect SPNs. Dopamine deprivation impaired striatal feedback transmission disrupting the ability of a neuronal pool to arrest the firing of another neuronal pool. We demonstrate that feedback inhibition among SPNs is strong enough to control the firing of cell ensembles in the striatal microcircuit. However, to be effective, feedback inhibition should arise from synchronized pools of SPNs whose targets are other SPNs pools.

\section{Introduction}

Parkinson's disease is a neurodegenerative disorder characterized by the loss of dopamine (DA) afferents innervating basal ganglia nuclei, including the striatum. The most abundant DA targets in the striatum are spiny projection neurons (SPNs). They form the "direct" and "indirect" basal ganglia pathways, whose balanced activity is proposed to control action selection (Albin et al., 1989; DeLong, 1990; Bar-Gad and Bergman, 2001; Obeso et al., 2004; Kravitz et al., 2010; Aceves et al., 2011; Gerfen and Surmeier, 2011). SPNs from the direct pathway (dSPNs) express $D_{1} D A$ receptors and project to the internal segment of the globus pallidus and substantia nigra reticulata. Indirect $\mathrm{SPNs}$ (iSPNs) express $\mathrm{D}_{2} \mathrm{DA}$

Received Oct. 5, 2012; revised Jan. 16, 2013; accepted Jan. 27, 2013.

Author contributions: V.G.L.-H., E.G., R.D.-C., and J.B. designed research; V.G.L.-H. performed research; L.C.-R., D.T., and T.F. contributed unpublished reagents/analytic tools; V.G.L.-H., L.C.-R., and J.B. analyzed data; V.G.L.-H., L.C.-R., E.G., and J.B. wrote the paper.

This work was supported by Investigacion Multidisciplinaria de Proyectos Universitarios de Liderazgo y Superacion Academica-Universidad Nacional Autónoma de México and Dirección General de Asuntos del Personal Académico-Universidad Nacional Autónoma de México Grant IN-205610 to J.B. and Grant IN-206010 to E.G. The Miguel Alemán A. C. Foundation, Consejo Nacional de Ciencia y Tecnología (México) Grant 98004 to E.G. and Grant 154131 to J.B., and the Mexico-Germany Agreement Consejo Nacional de Ciencia y Tecnología-Deutsche Forschungsgemeinschaft Grant 10110/193/10 FON.INST.-29-10 to J.B., V.G.L.-H. and L.C.-R. had Consejo Nacional de Ciencia y Tecnología doctoral fellowships. We thank Antonio Laville, Gabriela X. Ayala, Adriana Hernández, and Claudia Rivera for technical support, animal care, and advice.

The authors declare no competing financial interests.

Correspondence should be addressed to Dr. Jose Bargas, Instituto de Fisiología Celular, Universidad Nacional Autónoma de México, P.0. Box 70-253, México City, DF 04510 México. E-mail: jbargas@ifc.unam.mx.

DOI:10.1523/JNEUROSCI.4721-12.2013

Copyright $\odot 2013$ the authors $\quad 0270-6474 / 13 / 334964-12 \$ 15.00 / 0$ receptors and project to the external segment of the globus pallidus (GPe) (Gerfen and Young, 1988; Gerfen and Surmeier, 2011). dSPNs and iSPNs can be identified using bacterial artificial chromosome $(B A C)$ transgenic mice expressing enhanced green fluorescent protein (eGFP) associated with DA receptor promoters (Gerfen and Surmeier, 2011). Global actions of each pathway elicit opposite actions (Kravitz et al., 2010, 2012). A current model of Parkinsonism posits that DA depletion increases the activity of iSPNs and represses the activity of dSPNs, leading to an unbalanced striatal microcircuit output (Obeso et al., 2004).

"Feedback inhibition" refers to connections among SPNs through local axon collaterals (Plenz, 2003). These connections have been underrated because paired recording studies have shown that their impact during unitary synaptic events is commonly not enough to arrest action potential firing in target SPNs (Koos et al., 2004; Tepper et al., 2004, 2008, 2010). Unitary synaptic events among SPNs are usually of comparative lower amplitude than events coming from interneurons (Czubayko and Plenz, 2002; Tunstall et al., 2002; Plenz, 2003; Koos et al., 2004; Tecuapetla et al., 2007, 2009; Taverna et al., 2008). Therefore, to be effective, connections from several SPNs should converge on the same target neurons (Tepper et al., 2004; Gittis and Kreitzer, 2012). Abundant local axon collaterals from SPNs may converge on their target cells (Guzman et al., 2003; Chuhma et al., 2011), but, if that is the case, their impact has not been demonstrated at the microcircuit level.

Pools of SPNs can fire in synchrony alternating their discharge with other neuronal pools forming activity sequences (Carrillo- 
Reid et al., 2008, 2011). During experimental Parkinsonism, feedback inhibition is disrupted (Taverna et al., 2008; Tecuapetla et al., 2009) and the sequential activity is abolished (Jáidar et al., 2010). Consequently, a main goal of the present work is to observe whether synchronous feedback inhibition is strong enough of repressing firing in neighboring SPNs. We demonstrate that feedback inhibition depends on the number of recruited neurons and is capable to repress the firing of SPNs pools. This pool-topool feedback inhibition is altered after DA deprivation. Therefore, striatal GABAergic feedback transmission is a target for antiparkinsonian therapeutics.

\section{Materials and Methods}

Slice preparation. All the experiments were performed in accordance with the National Institutes of Health Guide for Care and Use of Laboratory Animals and followed the National University of Mexico guidelines for the use of animals in biomedical experiments. BAC $D_{1}$ and $D_{2} e G F P$ male mice, between postnatal days 25-30 (PD25-PD30) or male Wistar rats (PD14-PD30) were used. Essential methodology has been published previously (Carrillo-Reid et al., 2008; Jáidar et al., 2010). Briefly, animals were anesthetized (isofluorane) and perfused transcardially with an icecold perfusion solution (in $\mathrm{mm}$ ): 225 sucrose, $2.5 \mathrm{KCl}, 7 \mathrm{MgCl}_{2}, 0.5$ $\mathrm{CaCl}_{2}, 28 \mathrm{NaHCO}_{3}, 7$ glucose, 1 ascorbic acid, and 3 pyruvate ( $\mathrm{pH} 7.4$ with $\mathrm{NaOH}$; saturated with $95 \% \mathrm{O}_{2} / 5 \% \mathrm{CO}_{2}$ ). The brain was removed quickly and placed into ice-cold $\left(4^{\circ} \mathrm{C}\right)$ bath saline containing the following (in mM): $123 \mathrm{NaCl}, 3 \mathrm{KCl}, 1 \mathrm{MgCl}_{2}, 2.0 \mathrm{CaCl}_{2}, 25 \mathrm{NaHCO}_{3}$, and 15 glucose ( $\mathrm{pH} 7.4$ with $\mathrm{NaOH}, 298 \mathrm{mOsm} / \mathrm{l}$ with glucose; saturated with $95 \% \mathrm{O}_{2} / 5 \% \mathrm{CO}_{2}$ ). Parasagittal neostriatal slices ( $250 \mu \mathrm{m}$ thick) were cut using a vibratome and incubated in the bath saline at room temperature for at least $1 \mathrm{~h}$ before recording (Tecuapetla et al., 2007; Flores-Barrera et al., 2010). These slices have proved optimal for the antidromic stimulation of striatofugal axons (Guzman et al., 2003).

Optical recordings of neuronal populations with single-cell resolution. We obtained slice images from $B A C$ mice with eGFP labeled neurons from either $D_{1}-e G F P$ or $D_{2}$-eGFP mice. The coordinates of each neuron and landmarks of the field of view using differential interference contrast microscopy were stored for reference. Slices from either rats or BAC mice with eGFP-labeled cells were incubated at room temperature in the dark for $20 \mathrm{~min}$ in the presence of $10 \mu \mathrm{M}$ fluo 4 -AM (Tef Laboratories or Invitrogen) in $0.1 \%$ dimethylsulphoxide $\left(35^{\circ} \mathrm{C}\right)$ equilibrated with $95 \%$ $\mathrm{O}_{2} / 5 \% \mathrm{CO}_{2}$. Then, slices were perfused continuously with control saline (see above) in a chamber located on the stage of an upright microscope equipped with $10 \times, 0.3 \mathrm{NA}$ water-immersion objective (Eclipse E600FN; Nikon). The same field of view (coordinates, landmarks, and eGFP ${ }^{+}$ cells) was recovered after fluo-loading. Fluo-4 loaded eGFP ${ }^{-}$and $\mathrm{eGFP}^{+}$cells exhibited calcium transients elicited by actions potentials. Differential interference contrast images before and after fluo-loading had to be the same pixel-to-pixel comparisons with overlap correlation coefficient $>0.95$ to continue the experiment. We could observe neuronal activity in identified $\mathrm{GFP}^{+}$cells (either dSPNs or iSPNs) and GFP ${ }^{-}$ cells. Light pulses at $488 \mathrm{~nm}(50-100 \mathrm{~ms}$ exposure) were delivered to the preparation with a Lambda LS illuminator (Sutter Instruments) connected to the microscope via fiber optics. Experiments were performed at room temperature. Series of images were acquired with a cooled digital camera (CoolSNAP ES ${ }^{2}$, Photometrics, Roper Scientific) at 100-250 ms per frame using Image Pro (Photometrics; Roper Scientific). The field of view was $800 \times 600 \mu \mathrm{m}$ in size $1 \mathrm{~mm}$ from the stimulation site. Short movies $(\sim 120 \mathrm{~s}$ per epoch) were taken at time intervals of 5-20 min during $\geq 2 \mathrm{~h}$. Active cells were identified by their spontaneous or evoked calcium transients. Maps of visualization fields are illustrated, filled contours or circles indicate active neurons at some time during the experiment, and empty contours show cells loaded with fluo- 4 but that remained inactive or nonresponsive during the experiment. Cells nonresponsive to antidromic field stimulation could be present for two main reasons: (1) their axons were not in the range affected by the stimulation electrode; they are not activated at all or their antidromic invasion is too weak to generate a significant calcium transient; and (2) their axons were in this range, but their antidromic activation was arrested by the ortho- dromic inhibition from neighboring neurons that were antidromically activated by the same electrode. Here, we assume that the antidromic activation of this later group would be better disclosed when inhibition coming from neighboring neurons is blocked with $\mathrm{GABA}_{\mathrm{A}}$-receptor antagonists, or else, by somatic depolarization. These antagonists are not supposed to affect those cells that did not fire because they were out of the range of the stimulation electrode or whose antidromic invasion did not elicit a significant calcium transient because feedback inhibition is not a main cause of their weak activation. In rat experiments, the total number of fluo-4-loaded neurons in the visualization field was determined at the end of the experiment with a $1 \mathrm{~s}$ puff of $30 \mathrm{~mm} \mathrm{KCl}$. Calcium transients and electrophysiological responses were stored and analyzed off-line (see Results). In general, visualization fields showed many nonresponding neurons that were loaded with the fluorophore.

Image analysis. Image analysis was performed with ImageJ (version $1.42 \mathrm{q}$, National Institutes of Health) and custom-made programs written in MATLAB (MathWorks) as previously described (Carrillo-Reid et al., 2011). Briefly, active neurons were semiautomatically identified and numbered, a 2D coordinate for each cell was assigned, and contours of somata were drawn (contours are substituted by empty circles in most figures). Calcium transients represent changes in fluorescence: $\left(F_{i}-\right.$ $\left.\mathrm{F}_{\mathrm{o}}\right) / \mathrm{F}_{\mathrm{o}}$, where $\mathrm{F}_{\mathrm{i}}$ denotes the fluorescence intensity at any frame and $\mathrm{F}_{\mathrm{o}}$ denotes the basal fluorescence of each neuron. eGFP ${ }^{+}$cells displayed calcium transients similar to those exhibited by $\mathrm{eGFP}^{-}$cells. The time derivative of the calcium transient has the same duration as the neuronal electrical activity and can be used as a measure of the bursting activity of neurons (significance: $>2.5$ times the SD of the noise) (Carrillo-Reid et al., 2009). Thus, bursting of dozens of neurons can be followed over time. Recordings were inspected manually to remove artifacts (Carrillo-Reid et al., 2008). Raster plots as binary matrixes were built with the activity of many recorded neurons. Rows represent different active neurons, and columns represent frames of image sequences. Only calcium transients elicited by neurons were analyzed. Glial signals were easily distinguished and discarded (Carrillo-Reid et al., 2008).

Electrophysiology. Simultaneous calcium imaging and electrophysiological recordings were obtained in designed experiments with an Axoclamp 2B amplifier (Molecular Devices) under different pharmacological conditions. Signals were filtered at $1-3 \mathrm{kHz}$ and digitized at $3-9 \mathrm{kHz}$ with an AT-MIO-16E4 board (National Instruments) in a cloned PC. Data acquisition used software designed in the LabVIEW environment. Patch pipettes (3-6 M $\Omega$ ) were filled with (mM): $115 \mathrm{KH}_{2} \mathrm{PO}_{4}, 2 \mathrm{MgCl}_{2}, 10$ HEPES, 0.5 EGTA, $0.2 \mathrm{Na}_{2}$ ATP, and $0.2 \mathrm{Na}_{3} \mathrm{GTP}$. Biocytin $0.5 \%$, and fluo-4 salt $(20-100 \mu \mathrm{M})$ were added to the recording pipettes in several experiments. Whole-cell access resistance was in the range of 5-10 M $\Omega$ and was continuously monitored. Experiments were abandoned if changes $>20 \%$ of access resistance were encountered. No cell capacitance, series resistance, or liquid junction potential compensations were made. Digitized data saved on disk was analyzed with commercial software (Origin version 6. Microcal).

To evaluate the calcium transients elicited by antidromic action potentials, whole-cell current-clamp targeted recordings of SPNs were performed when neurons responded to antidromic stimulation $(\times 40$ water-immersion objective). Antidromic action potentials were evoked with field stimulation in the external globus pallidus (GPe) using bipolar concentric tungsten electrodes (12-25 $\mu \mathrm{m}$ at the "pencil shaped" tip; 60 $\mathrm{k} \Omega \mathrm{dc}$ resistance; FHC). When no drugs are used, antidromic action potentials (or currents) are followed by orthodromic synaptic responses and, according to stimulus intensity, by orthodromic action potentials or currents (Guzman et al., 2003; their Fig. 2A). For that reason, $10 \mu \mathrm{M}$ CNQX plus $50 \mu \mathrm{M}$ APV were used to block orthodromic excitatory synaptic events from corticofugal axons in both electrophysiological and imaging experiments. In this way, antidromic activation can be used to isolate orthodromic inhibition. In addition, to isolate inhibitory currents, $1 \mu \mathrm{M}$ QX-314 was used inside the recording pipette to block antidromic action currents in electrophysiological experiments. A $20 \mathrm{~Hz}$ train of 10 stimuli (each stimulus: $200 \mathrm{~ms}$ duration; $<30 \mu \mathrm{A}$ strength) was delivered with a computer interface. Isolation units (Digitimer) were used to adjust stimulus intensity. Distance between stimulating electrode and recorded cells was $\sim 1 \mathrm{~mm}$. Calcium transients elicited by antidromic 
action potentials were compared with those elicited by action potentials evoked with direct stimulation. The calcium transients elicited by antidromic action potentials are proportional to the number of spikes fired and similar to those elicited by direct stimulation.

6-OHDA lesions. Hemiparkinsonian animals, rats or BAC mice, were obtained as previously reported (Jáidar et al., 2010). Briefly, animals were anesthetized with ketamine ( $85 \mathrm{mg} / \mathrm{kg}$, i.p.) plus xylazine ( $15 \mathrm{mg} / \mathrm{kg}$, i.p) while immobilized on a stereotactic frame. Each animal received a unilateral injection of 6-OHDA ( $8 \mu \mathrm{g}$ in $0.2 \mu \mathrm{l}$ with $0.2 \mathrm{mg} / \mathrm{ml}$ of ascorbic acid) $0.1 \mu \mathrm{l} / 1 \mathrm{~min}$ in the substantia nigra pars compacta (substantia nigra pars compacta coordinates: $3.8 \mathrm{~mm}$ caudal, $1.8 \mathrm{~mm}$ lateral to bregma, and $7.1 \mathrm{~mm}$ ventral to the skull surface in rats and $2.6 \mathrm{~mm}$ caudal, $0.7 \mathrm{~mm}$ lateral to bregma and $4.5 \mathrm{~mm}$ ventral to the skull surface in postnatal day 21 mice).

Turning behavior. As described previously (e.g., López-Huerta et al., 2012), the degree of DA deprivation was tested provoking turning behavior $8 \mathrm{~d}$ after the surgery using automated rotometers and amphetamine $(4 \mathrm{mg} / \mathrm{kg}$, i.p.). This routine has been reported on several occasions (6OHDA model) and here will not be reported in the Results, but only as a method to obtain hemiparkinsonian animals. Left and right full body turns were recorded for $90 \mathrm{~min}$ by a home-made computerized monitor. Animals showing $>500$ turns ipsilateral to the injected side were considered for further experiments.

Drugs. CNQX, APV, bicuculline, gabazine, biocytin, QX-314 (SigmaAldrich) were freshly prepared and added to the perfusion during the experiment in the required concentration. Fluo-4 AM was acquired from Invitrogen.

Statistical methods. Correlated calcium transients from different cells were detected as simultaneous activations per trial. To determine the $p$ value of simultaneous transients occurring by chance, the distribution under the null hypothesis of independent transients using Monte Carlo simulations with 1000 replications was computed (Carrillo-Reid et al., 2008). Degree of correlation between active cells was calculated with the Jaccard correlation coefficient. Pseudocolored maps illustrate the correlation matrix.

To analyze microcircuit dynamics, $D \times N$ matrices were constructed from the raster plots (see above). $D$ represents the number of active neurons in a set of experiments and $N$ denotes the firing of cells during $100-500 \mathrm{~ms}$ time bins. Synchronous activity was detected as column vectors (neuronal vectors or pools) in the raster plot where each vector element is formed by the calcium transients displayed by each neuron during the time bin. The histogram of this raster adds up activity of different neurons so that column vectors are seen as peaks of synchronization (at the bottom of raster plots). Thus, synchronized/correlated bursting of different cells was identified (Carrillo-Reid et al., 2011). In the present report, a direct causal relationship between antidromic stimulation and a column vector of synchronized neurons was attained at will. However, after repetitive stimulation in control animals and in 6-OHDA-injured animals, synchronization could occur spontaneously (Jáidar et al., 2010). In such cases, sets of vectors alternating their activity were used to record microcircuit dynamics (Carrillo-Reid et al., 2009). Distribution-free statistical procedures were used to find data significance at the level $p<0.05$ with commercial software (Systat version 7; SPSS).

Immunofluorescence. To find the best places for stimulation and recording, $500 \mu \mathrm{m}$ brain slices form either $D_{1}-e G F P$ or $D_{2}-e G F P$ mice were placed in a chamber with constant perfusion. A broken pipette was located over the GPe to instill biocytin for $2 \mathrm{~h}$. Thereafter, brain slices were perfused by other 3-4 h to allow biocytin transport. Then, slices were fixed overnight with $4 \%$ paraformaldehide in $0.1 \mathrm{M} \mathrm{PBS,} \mathrm{pH} 7.4$, then infiltrated with a solution of sucrose $30 \%$ and cut in a vibratome in 40 $\mu \mathrm{m}$ sections. The sections were incubated $4-6 \mathrm{~h}$ in PBS solution containing 0.2 Triton X-100 and streptavidin conjugated to CY3 $(6 \mu \mathrm{l} / \mathrm{ml}$; Vector Laboratories) to label the area of interest. Sections were mounted in an antiquenching media (Vectashield, Vector Laboratories) and examined under a confocal microscope (MRC-1024; Bio-Rad) equipped with a krypton-argon mixed-gas laser. Two laser lines emitting at 490 and $560 \mathrm{~nm}$ were used for exciting GFP and CY3, respectively (retrograde and anterograde biocytin transport reveals the best places to locate recording and stimulation electrodes).

\section{Results \\ Antidromic stimulation activates GABAergic feedback transmission in striatal slices}

The preparation to preferentially activate SPNs antidromically from the GPe has been described previously (Guzman et al., 2003; Salgado et al., 2005; Tecuapetla et al., 2007). We performed whole-cell recordings of SPNs to study the orthodromic GABAergic response elicited onto neighboring neurons after antidromic stimulation ( $n=55$ SPNs; scheme in Fig. $1 A$ ). Collision tests between action potentials evoked with direct current injection and those evoked by field stimulation confirmed that SPNs can be activated antidromically from the GPe (Fig. 1A2, stimulus artifact denotes antidromic stimuli). Voltage responses to current steps confirm electrophysiological profile of recorded SPNs (Fig. 1A3,A4). To avoid orthodromic excitatory currents and orthodromic firing resulting from cortifugal axons (Guzman et al., 2003; their Fig. 2A), we blocked glutamatergic transmission by adding $10 \mu \mathrm{M}$ CNQX and $50 \mu \mathrm{M}$ APV. Therefore, the orthodromic synaptic currents produced by neighboring antidromically activated cells in a given recorded SPN could be completely blocked by $10 \mu \mathrm{M}$ bicuculline or gabazine (Fig. $1 B$, time course), demonstrating that they are GABAergic, orthodromic, inhibitory postsynaptic currents (IPSCs) elicited by antidromic activation (IPSCs) (López-Huerta et al., 2012). In addition, to avoid the firing of antidromic spikes (Guzman et al., 2003; their Fig. 2A) when synaptic events were recorded, QX-314 was used intracellularly (see Materials and Methods). Figure $1 C$ shows representative IPSCs. Synaptic currents obtained after GPe stimulation are facilitating or weakly depressing (Guzman et al., 2003; Salgado et al., 2005; Tecuapetla et al., 2007). Figure $1 D-F$ shows that many eGFP-labeled neurons (green) either from $\mathrm{D}_{1}$-eGFP (Fig. $1 E$ ) or $\mathrm{D}_{2}$-eGFP (Fig. $1 F$ ) colocalize with the CY3 marker (yellow) used to reveal biocytin staining (see Materials and Methods). Both dSPNs and iSPNs could be recorded after antidromic stimulation from the GPe.

\section{Calcium transients evoked by antidromic stimulation in striatal SPNs}

To visualize the neurons recruited by antidromic stimulation, we performed simultaneous whole-cell recordings and calcium imaging in SPNs. Figure $2 A$ shows a BAC- $D_{1}$ mouse slice used to identify $\mathrm{GFP}^{+}$SPNs (experiments used either $B A C-D_{1}$ or $D_{2}$ mice). GFP fluorescent cells can be observed in the recording area before fluo-4 loading (Fig. 2A1): a zoom of the central area is shown at the right before and after loading (Fig. $2 A 2$ and Fig. 2A3, respectively); exactly the same area is conserved to consider slices for further experiments (arrows indicate fluo-loaded [active] cells that are $\mathrm{GFP}^{-}$). Contour maps of $\mathrm{GFP}^{+}$cells are obtained for later identification and/or targeted electrophysiological experiments (e.g., Fig. 2B); responsive cells are represented by colors and nonresponsive cells by empty contours. Figure $2 C$ left illustrates fluo-4 fluorescence in a neuron targeted for electrophysiological recordings. This neuron was $\mathrm{eGFP}^{+}$from a $B A C-D_{1}$ mouse (Fig. 2C1). It was also filled with biocytin (Fig. $2 \mathrm{C} 2$, red $\mathrm{CY} 3$ ) to observe its dendritic morphology and was immunoreactive against substance $\mathrm{P}$ antibodies (Fig. 2C3, blue CY5). The same procedures were attained with iSPNs from BAC- $\mathrm{D}_{2}$ mice (not illustrated). Figure $2 D, E$ illustrates that calcium transients can be elicited in the same neuron when action potentials are evoked antidromically or by current injection, re- 

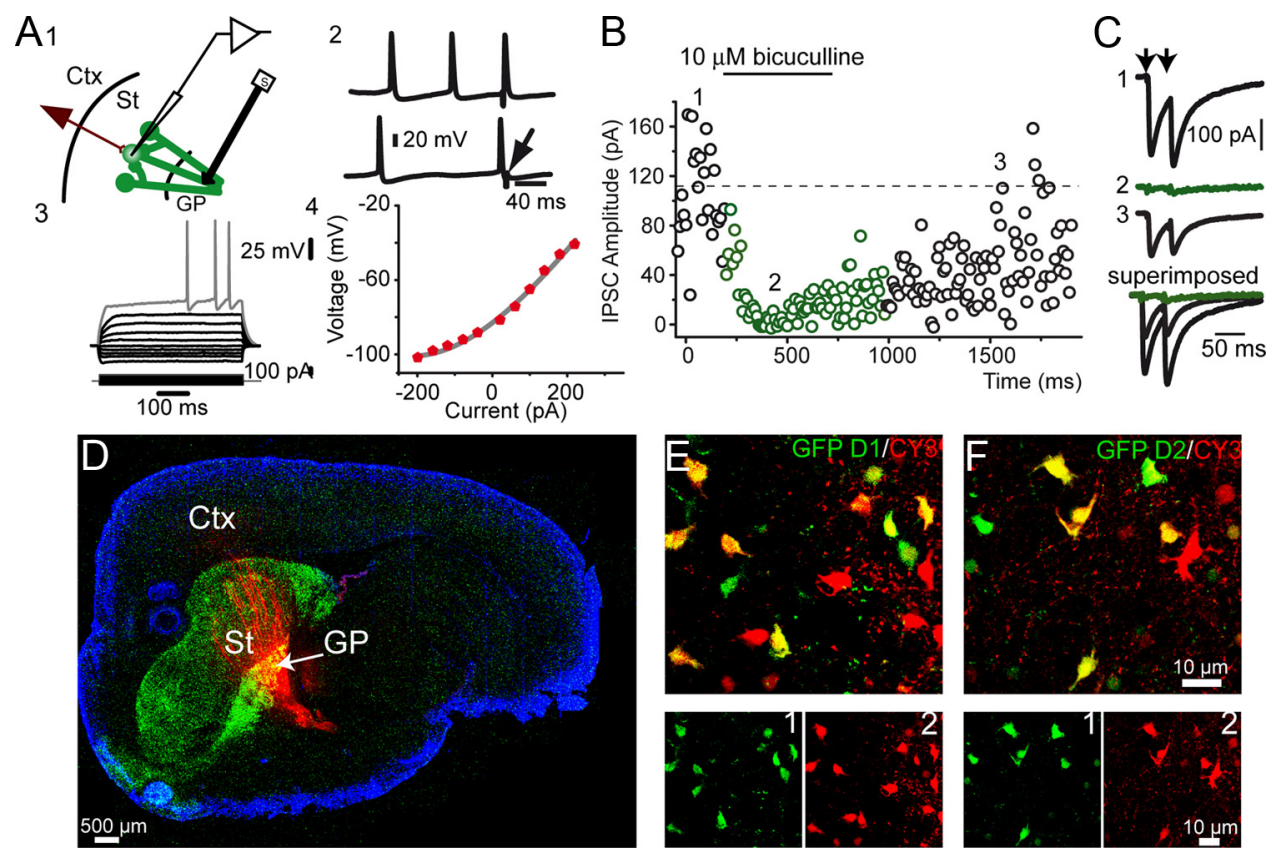

Figure 1. Antidromic activation of spiny projection neurons elicits GABA release from their axon collaterals. A1, Anatomical scheme of the antidromic stimulation (S) of SPN axons (green) passing through or reaching the GPe. Activated axon collaterals make synapses onto recorded SPNs (Tecuapetla et al., 2007). The possible contribution of excitatory projections (symbol: brown neuron) was blocked by $10 \mu \mathrm{m}$ CNQX plus $50 \mu \mathrm{m}$ APV. A2, Collision tests between SPN action potentials elicited by direct depolarization and antidromic stimulation (artifact corresponds to antidromic spike). A3, Recordings of voltage responses to hyperpolarizing and depolarizing current injections (top) in an SPN in current-clamp mode. There is inward rectification and time to first action potential. $\boldsymbol{A 4}$, Current-voltage relationship (I-V plot) from records at left. $\boldsymbol{B}$, Time course of IPSCs amplitudes (IPSCs) elicited by antidromic stimulation from the GPe in a recorded postsynaptic neuron; $10 \mu \mathrm{m}$ bicuculline blocked IPSCs completely and reversibly (green empty circles). C, Representative IPSCS (paired responses) taken from the time course as indicated by numbers. $D$, Biocytin injection in the $\mathrm{GPe}$ (red: $\mathrm{CY} 3$ ) shows retrograde labeling of striatal fibers passing through or arriving to this nucleus in a sagittal slice. Green labeling is $\mathrm{GFP}_{\mathrm{n}}$ a $\mathrm{D}_{2} \mathrm{BAC}$ mouse. Blue labeling corresponds to $\mathrm{DAPI}$ stain used to delineate the outline of the sagittal slice to improve contrast. $\boldsymbol{E}, \boldsymbol{F}$, Double-stained neurons in BAC mice showing $\mathrm{GFP}^{+}{ }^{+}$(green) and biocytin (red) labeled neurons (GFP ${ }^{-}$); the stimulus recruits neurons from both direct and indirect pathways (yellow is the merge of red and green labels).

spectively: Trains of antidromic action potentials (Fig. 2D) produce calcium transients similar to those elicited by action potentials evoked by direct current injections (Fig. $2 E)(n=10)$. Single action potentials (separated from other spikes by longer times) did not elicit significant calcium transients for the present purposes $(>2.5 \mathrm{SD}$ from the noise). Significant calcium transients can be recorded reliably with the firing of two or more action potentials (Carrillo-Reid et al., 2008; Jáidar et al., 2010). Calcium transients $(\Delta \mathrm{F} / \mathrm{F})$ could be obtained from $\mathrm{GFP}^{-}$and $\mathrm{GFP}^{+}$cells. More responses are illustrated below (second row) at a slower time base (Fig. 2D2,E2). Calcium transients are evoked by action potentials (Fig. 2D3,E3). Time derivatives of calcium transients exhibit durations similar to those from electrical responses (Fig. 2D4,E4). Hyphenated line shows significant threshold ( $>2.5$ SD of the noise). Because time derivatives of calcium transients represent the duration of electrical activity, they can be used to reconstruct the electrical activity of active neurons plotted as points in raster plots (Fig. 2D,E, bottom) (Carrillo-Reid et al., 2008).

\section{Antidromic stimulation recruits and synchronizes pools of SPNs}

To study transmission among SPNs at the microcircuit level, we used calcium imaging with single-cell resolution ( $n=63$ slices) (Carrillo-Reid et al., 2008, 2009, , 2011). Trains of 10 stimuli (see Materials and Methods) were used while neuronal activity was recorded by dynamic calcium imaging allowing the visualization of recruited neurons.

The raster plot in Figure $3 A$ shows that antidromic stimulation (arrows) evokes the synchronized firing of several SPNs (see column vectors in red; each row represents a different neuron). To evaluate the dependency of responding neurons on stimulation strength, we increased stimulus intensity while counting the number of fluorescent neurons that contributed to evoked peaks of synchronization. Raster plots (e.g., Fig. 3A, top; 5 movies/3 min each) and activity histograms (Fig. $3 A$, bottom) clearly show that neuronal vectors and antidromic synchronization peaks (arrows) had more responding neurons with stronger stimulus strengths. Some neurons activate only at the higher stimulus strengths, showing that striatofugal axons are sequentially recruited as stimulus intensity is increased. Indeed, this relationship was well fitted to a three parameter sigmoid function (Fig. $3 B)$ of the form: $N(i)=N \max /\{1+\exp [-k(i-i h)]\}$, where: $N(i)$ is the number of neurons recruited as a function of stimulus strength (i), Nmax is the maximal number of neurons recruited (saturation), $k$ is the slope factor, and $i$ is the stimulus strength needed to recruit half of the neurons. Parameter averages were as follows: $N \max =34 \pm 7$ neurons; $k=4.5 \pm 0.1$ (neurons $/ \mu \mathrm{A})$, and $i h=13 \pm 1 \mu \mathrm{A}(n=6)$. Illustrated sample was taken from rats, but similar results were obtained in mice $(n=3)$.

If SPNs are recruited antidromically following a sigmoidal function, then recruited SPNs should inhibit neighboring neurons orthodromically as manifested by IPSCs recorded in a target neuron. IPSCs also increase sigmoidally as a function of stimulus strength (Fig. 3C, arrows). Indeed, IPSC amplitude also obeys a sigmoid function (Tecuapetla et al., 2005) of the form: $A(i)=$ $A \max /\{1+\exp [-k(i-i h)]\}$, where $A(i)$ is IPSC amplitude as a function of stimulus strength (i), Amax = is maximal IPSC amplitude, $k$ is the slope factor, and $i h$ is the stimulus strength needed to reach a half-maximal IPSC amplitude (Fig. $3 C$, inset). 
A
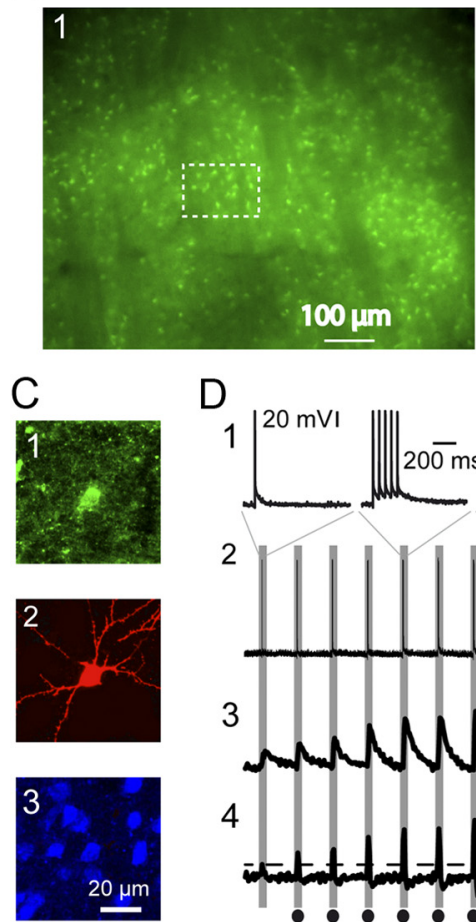

$\mathrm{D}$
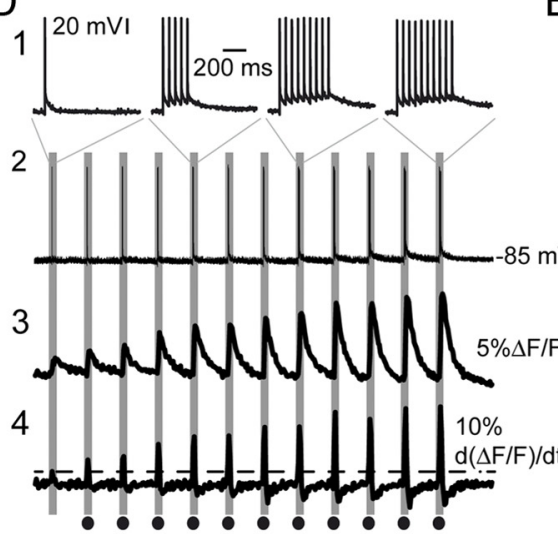

B

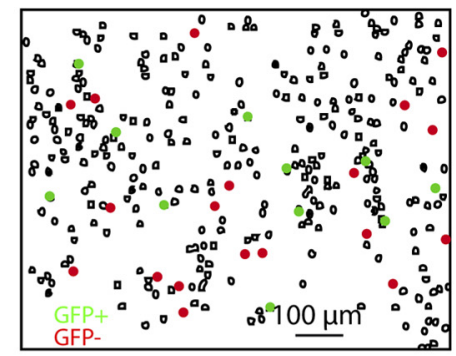

E
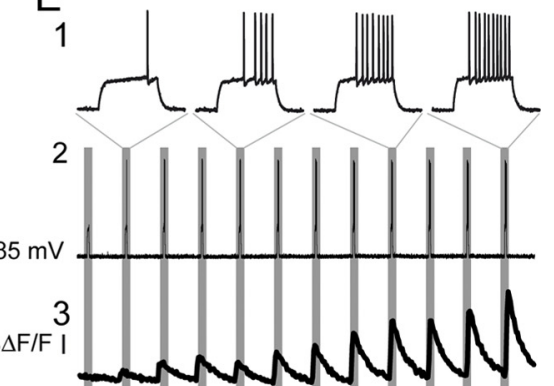

4

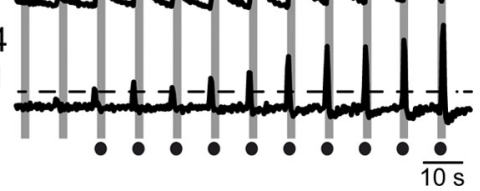

Figure 2. Calcium transients evoked in antidromically activated striatal projection neurons. $\boldsymbol{A}$, Area of the dorsal striatum $(860 \times 670 \mu \mathrm{m})$ showing eGFP ${ }^{+}$neurons. $\boldsymbol{A}$, Different experiments were performed with either $\mathrm{D}_{1}$-eGFP or $\mathrm{D}_{2}$-eGFP mice. $\boldsymbol{A} \mathbf{2}$, An area marked with a rectangle in $\boldsymbol{A} \mathbf{1}$ is magnified to see a group of eGFP-labeled neurons. $\boldsymbol{A} \mathbf{3}$, Same area after 20 min incubation with $10 \mu \mathrm{m}$ fluo-4 AM. Arrows denote two active fluo-loaded cells that are eGFP ${ }^{-}$. B. Contour detection of eGFP ${ }^{+}$cells and fluo-4 AM-loaded cells. Green and red dots represent neurons responsive to antidromic stimulus, which were either $\mathrm{GFP}^{+}$or GFP ${ }^{-}$, respectively; that is, cells that belong to either the direct or indirect pathway. C1, Fluorescent image of a fluo-4 AM-loaded SPN during antidromic stimulation. This particular example was eGFP ${ }^{+}$(green) from a $\mathrm{D}_{1}-\mathrm{BAC}$ mouse. C2, Biocytin labeling (red using $\mathrm{CY} 3$ ) through the recording electrode revealed a typical arborization of SPNs. C3, Immunofluorescence against substance P (blue using CY5) confirmed this neuron as dSPN. Similar results were obtained with enkephalin-immunoreactive iSPNs. D, Simultaneous calcium imaging and electrophysiology in an eGFP ${ }^{+}$neuron from a BAC-D mice. D1, Action potentials evoked by one or a few antidromic stimuli from the GPe in the same neuron. $\mathbf{D 2}$, Trains of antidromic action potentials are illustrated in a slower time base. D3, Antidromic stimulation elicits calcium transients whose amplitude is proportional to the number of action potentials fired. D4, First time derivative of calcium transients was used to detect events that are $>2.5 \mathrm{SD}$ of the basal noise. $\boldsymbol{E}$, Calcium transients elicited antidromically are similar to calcium transients elicited by somatic current injections showing that calcium transients are mostly the result of calcium entry during action potentials. E1, Action potentials evoked by direct intracellular depolarizing current steps (data not shown) of increasing magnitude in the same SPN. E2, Same responses at a slower time base. E3, Calcium transients recorded during evoked action potentials. E4, Significant detections (hyphenated line) were fixed $>2.5$ SD of the noise. Significant events denoted by dots were used to construct raster plots.

Results are as follows: Amax $=156 \pm 10 \mathrm{pA}, k=6.8 \pm 3(\mathrm{pA} /$ threshold units), and $i h=1.3 \pm 0.06$ threshold units, suggesting that as stimulus strength increases the inhibition received by a postsynaptic neighboring SPN increases because the number of recruited presynaptic SPNs converging on the recorded cell also increases. Notably, IPSCs evoked by stimulation of pallidostriatal fibers follow a different (step) function in different recorded postsynaptic neurons (Tecuapetla et al., 2005; Connelly et al., 2010; Aceves et al., 2011). Pallidostriatal IPSCs also exhibit much larger saturating amplitudes (Tecuapetla et al., 2005; Miguelez et al., 2012). These differences suggest that most evoked inhibition in the present experimental conditions comes from SPNs (see Discussion). In conclusion, IPSC amplitude increases in parallel with the recruitment of presynaptic SPNs (Czubayko and Plenz, 2002; Tunstall et al., 2002; Tecuapetla et al., 2007; Chuhma et al., 2011). But we wanted to observe the SPNs that are inhibited by feedback inhibition evoked by antidromic stimulation because the question of how many neurons are inhibited by a pool of SPNs acting in synchrony has remained unsolved.

To identify recruited SPNs, we used BAC mice. We chose stimulus strengths that were able to recruit $>20$ neurons responding simultaneously (Fig. $3 D$, colored dots): green dots indicate $\mathrm{eGFP}^{+}$neurons (either from $D_{1}-e G F P$ or $D_{2}-e G F P B A C$ mice), red dots indicate $\mathrm{eGFP}^{-}$neurons, and empty circles indi- cate nonresponsive neurons (without significant calcium transients). Activity histogram (Fig. 3D, bottom) illustrates the evoked peak of synchronization corresponding to the neuronal vector above (see Materials and Methods). A contour map (Fig. $3 E$ ) shows the location of active neurons in the field of view: green circles for $\mathrm{eGFP}^{+}$and red circles for $\mathrm{eGFP}^{-}$cells. Empty circles are fluo-loaded nonresponding cells (see Material and Methods). Many cells did not respond to stimulus.

In each experiment, we counted the number of $\mathrm{eGFP}^{+}$and $\mathrm{eGFP}^{-}$neurons that responded to antidromic stimulation; $45 \pm$ $5 \%$ of the neurons were $\mathrm{eGFP}^{+}$and $55 \pm 5 \%$ were $\mathrm{eGFP}^{-}$in a sample of experiments with either $D_{1}-e G F P$ or $D_{2}$-eGFP $B A C$ mice (Fig. 3E, bottom; not significant), suggesting that antidromic stimulation in control conditions has the same probability of activating dSPNs and iSPNs even if GPe is the target of iSPNs (e.g., Gerfen and Young, 1988; Kita, 1993; Chuhma et al., 2011). We conclude that antidromic stimulation has no preference for arriving or passing axons and that $\mathrm{D}_{1}$-eGFP and $\mathrm{D}_{2^{-}}$ eGFP cells are activated nearly half and half in control conditions.

Neuron pool recruitment is time dependent

We investigated whether inhibition can be indirectly evaluated on antidromically responding neurons by observing their calcium transients. Pallidal afferents elicit a depressing inhibition in 
A
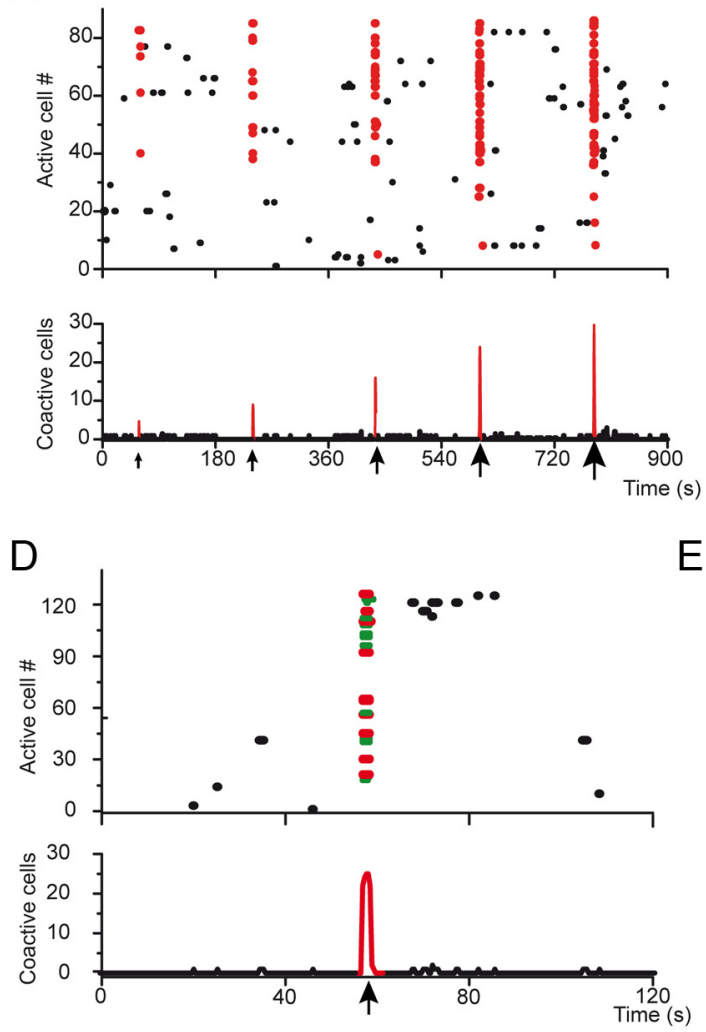

E
B

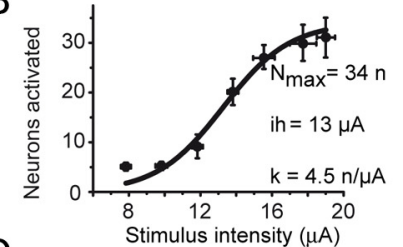

C

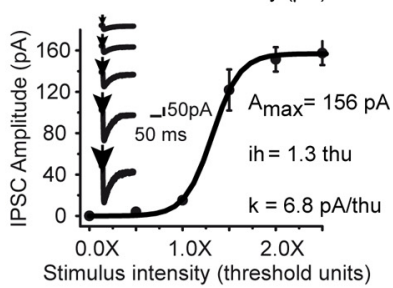

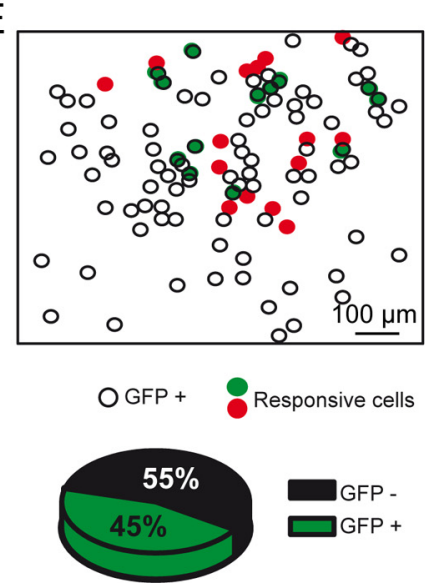

Figure 3. Neurons activated by antidromic stimulation from the GPe are from the direct and indirect basal ganglia pathways. $A$, Raster plot of antidromically induced synchronization of spiny neurons. Each row represents the firing of one cell, where $x$-axis $=$ time (seconds) and $y$-axis = active neurons. There is scarce spontaneous activity in the control (black dots). Arrows indicate antidromic stimulation. The number of active neurons increases as a function of antidromic stimulation intensity (symbolized by arrow size). Neuronal column vectors are synchronized by the stimulus (red dots). Histogram of overall activity (bottom) shows augmenting evoked peaks of synchronization, with each stimulus (arrows) indicating that more SPNs coactivate as a function of stimulus strength. $\boldsymbol{B}$, Plot showing an increase in neuronal recruiting as a function of stimulus strength $(\mu \mathrm{A})$. The fit was done with a three parameter logistic function of the form: $N(i)=N \max /\{1+\exp [-k(i-i h)]\}$, where $N(i)$ is the number of neurons made to fire as a function of stimulus strength $(i), k$ is a slope factor, and $i h$ is the stimulus strength needed to recruit half of the neurons. The function tends to saturation at N $\max =34 \pm 7$ neurons; $k=4.5 \pm 0.1$ (neurons $/ \mu \mathrm{A})$, and $i h=13 \pm 2 \mu \mathrm{A}(n=6)$. $C$, Intensity-amplitude plot of axon collaterals recruitment (IPSC amplitude) normalized to threshold units was fitted to the function: $A(i)=A \max / /\{1+\exp [-k(i-i h)]\}$, where $A(i)$ is IPSC amplitude as a function of stimulus strength, $A$ max $=$ is maximal IPSC amplitude, $k$ is the slope factor, and ih is the stimulus strength needed to reach a half-amplitude IPSC. The function tends to saturation at $A \max =156 \pm 10 \mathrm{pA}, k=7 \pm 3$ (pA/threshold units), and ih $=1.3 \pm 0.06$ threshold units, not significantly different from what has been described for connections between SPNs (Tecuapetla et al., 2005, 2007), but totally different from connections coming from pallidal neurons (Tecuapetla et al., 2005; Aceves et al., 2011). Inset, IPSC amplitude as a function of stimulus strength. As expected, a stronger evoked inhibition goes in parallel with the number of recruited SPNs. Above illustrated experiments were performed in rats, but similar results were obtained in BAC mice (see below). $D$, Example of the typical synaptic response elicited by antidromic stimulation in $B A C$ mice. During the stimulus, several neurons fire in synchrony: column of red and green dots (column vector). Green dots indicate eGFP ${ }^{+}$cells; red dots indicate eGFP ${ }^{-}$cells; and the histogram represents the sum of active neurons (middle). Either BAC- $D_{1}$ or BAC- $D_{2}$ cells were used in these experiments; therefore, eGFP ${ }^{-}$cells mostly corresponds to the unlabeled pathway that responds with fluo- 4 fluorescence during the stimulus. More than 20 neurons, eGFP ${ }^{+}$or eGFP $^{-}$fired, thus making up a peak of synchronization. $\boldsymbol{E}$, Location of responding and nonresponding cells in the field of view. Both eGFP ${ }^{+}$(green) and eGFP ${ }^{-}$(red) cells responded to the stimulus. Empty circles represent eGFP ${ }^{+}$neurons that did not respond to the stimulus. Experiments in $\mathrm{BAC}$ mice $(n=14)$ indicated that approximately half of the responding cells were eGFP ${ }^{+}$ neurons, whereas the other half were eGFP ${ }^{-}$neurons in either $\mathrm{D}_{1}$ - or $\mathrm{D}_{2}$-eGFP mice. This particular experiment used a $\mathrm{D}_{2}$-eGFPBAC mouse.

need of $>70$ s to recover (Tecuapetla et al., 2005; Connelly et al., 2010; Aceves et al., 2011; Atherton et al., 2011; Miguelez et al., 2012). Therefore, we tested whether the population response was cumulative at relatively briefer time intervals, $10 \mathrm{~s}$ (not enough for pallidal inhibition to recover) (Fig. $4 A$ ) or if it is stronger during the first stimuli as expected by the low pass filtering pro-

duced by a strongly depressing synapse (Fioravante and Regehr, 2011). It can be observed that inhibition was cumulative upon repeated stimulation; neuronal vectors decrease their total number of responding neurons along time (Fig. 4A, bottom, activity histogram): By the fifth stimulus, the neuron pool had approximately one-half of the original number of neurons, suggesting that frequent activation accumulates inhibition so as to arrest the firing of some antidromically recruited neurons within the evoked neuronal vector.

Next, we tested whether the population response to antidromic stimulus was stable through the time at more prolonged intervals (Fig. 4B). Raster plots and histograms show that the same stimulus strength almost recruits the same neurons every time at $120 \mathrm{~s}$ intervals (3 movies/3 min each, stimuli interval 3 $\min )$; the number of antidromically recruited neurons is maintained stable after each stimulus if the time to recover from inhibition is long enough (Fig. $4 B$, bottom, activity histogram). A spatial map shows that recruited neurons are more or less the same at different times (Fig. 4C). Nonetheless, nonresponding cells (empty circles) are intermingled with responding ones. Is this because their antidromic activation (or nonactivation) did not elicit a significant calcium transient for any reason (see Materials and Methods) or because some of them are being inhibited by other activated neurons? The correlation matrix of the whole image series (Fig. $4 D$, in pseudocolor) shows that mainly the same SPNs are entrained by repetitive antidromic stimulation. But notably, some neurons spontaneously active before the stimulus did not respond to the antidromic stimulus (blue lines). Similar results were obtained in rats and mice.

The experiment illustrated in Figure 5 suggests that, indeed, the antidromic firing of some cells was not enough to elicit a significant calcium transient. A cell that failed to elicit and antidromic action potential after each stimulus $(-62 \mathrm{mV}$ membrane potential) and therefore did not exhibit a significant calcium transient (Fig. 5A) was capable to fire an action potential after each stimulus and exhibited a significant calcium transient after DC depolarization of $5 \mathrm{mV}$ and a slight increase in stimulus strength (Fig. $5 B$ ). Raster plot and activity histogram in Figure $5 C$ illustrate that after cumulative inhibition (Fig. $4 A$, above) has decreased the size of a neuronal vector, a stronger stimulus strength is capable to recover vector amplitude $(n=6)$. These experiments suggest that some nonresponsive cells, as seen with calcium transients, may have weak antidromic invasion. 
One question is whether this weak antidromic invasion is the result of orthodromic inhibition exerted by neighboring cells. To test this hypothesis, we needed to show that $\mathrm{GABA}_{\mathrm{A}}$-receptor antagonists could have, in some cells, similar effects as those showed by DC depolarization or increased stimulus strength.

\section{Feedback inhibition suppresses the firing of striatal neuronal pools}

Next, we evaluated feedback inhibition at the microcircuit level by testing $\mathrm{GABA}_{\mathrm{A}^{-}}$ receptor antagonists while recording several neurons simultaneously. The raster plot in Figure $6 \mathrm{~A}$ shows that without stimulation there is scarce spontaneous activity and no significant synchronization (control). However, a clear column vector with its corresponding peak of synchronization is seen during the stimulus (arrow in middle frame; train of 10 pulses at 20 $\mathrm{Hz}$, each one had $0.2 \mathrm{~ms}$ and $\sim 14 \mu \mathrm{A}$ ) in a slice taken from a $B A C D_{1}$ mouse. Activated neurons could be eGFP ${ }^{+}$(green) or $\mathrm{eGFP}^{-}$(red). After addition of $10 \mu \mathrm{M}$ bicuculline (right frame), the same stimulus evoked a peak of synchronization that nearly doubled the number of responding neurons (Fig. 6A, bottom), suggesting that a reason why some neurons did not exhibit a significant calcium transient (nonresponding) was that they were being inhibited by neighboring cells. Figure $6 B$ depicts the spatial maps of the responsive neurons before and after the blockade of GABAergic transmission. The proportion of active $\mathrm{eGFP}^{+}$cells is changed after bicuculline exposure (10 $\mu \mathrm{M}$ gabazine in some experiments yielded the same results) (López-Huerta et al., 2012). Responsive eGFP ${ }^{-}$ neurons (red) are now in greater proportion. Also, in both conditions, the number of nonresponsive cells is the largest. Figure $6 C$ shows a summary of results in a sample of slices $(n=13$ slices; $p<0.003)$. Similar results were obtained in mice and rats and in the case of mice both BAC $\mathrm{D}_{1}$ and $\mathrm{D}_{2}$ were used.

The above experiments prompt the conclusion that feedback inhibition is the predominant inhibition activated in these conditions. However, because neuron to neuron inhibition among SPNs appears to be weak in cell focused studies (Koos et al., 2004; Tepper et al., 2004, 2008 Gustafson et al., 2006), we conclude that, acting collectively, the convergence of SPNs on other SPNs is enough to silence the antidromic firing of approximately as many neurons as those active in the control. Therefore, feedback inhibition amounts to a significant action when quantified at the microcircuit level (e.g., Guzman et al., 2003; Koos et al., 2004; Surmeier et al., 2011; Gittis and Kreitzer, 2012).

It has been found that the probability to obtain a connection between SPNs is higher within a range $<100 \mu \mathrm{m}$ between any two SPNs (Czubayko and Plenz, 2002; Tunstall et al., 2002; Koos et al., 2004; Tepper et al., 2004); that is, inhibition among SPNs is mainly local involving intermingled neighboring cells. Therefore, we searched for the distribution of distances between responsive neurons appearing after $\mathrm{GABA}_{\mathrm{A}}$-receptor antagonists and their neighbors responsive to antidromic stimulation before the antagonists were introduced (Fig. 6D). The result was coincident with that obtained with paired recordings (Czubayko and Plenz, 2002; Koos et al., 2004; Tecuapetla et al., 2007, 2009; Taverna et al., 2008): the median of the distribution was $40 \mu \mathrm{m}$ with a coefficient of variation $<1$ (Fig. 6D).

Next, we asked whether connections among iSPNs are stronger than those among dSPNs as experiments with paired recordings suggest (Taverna et al., 2008: Tecuapetla et al., 2009). To answer this question, we used $\mathrm{BAC}$ mice to observe whether responsive neurons appearing after $\mathrm{GABA}_{\mathrm{A}}$-receptor antagonists preserved the proportion observed before these antagonists were introduced: approximately half and half of each class: $\mathrm{D}_{1^{-}}$and $\mathrm{D}_{2}$-eGFP neurons (see above). The result is seen in Figure $6 E$ : the proportion is not preserved; among the neurons responding after $\mathrm{GABA}_{\mathrm{A}}$-receptor antagonists, there is a predominance of $\mathrm{D}_{2}$ eGFP neurons (iSPNs): $26 \pm 2 \%$ are $\mathrm{D}_{1}$-eGFP (dSPNs) and $59 \pm$ $2 \%$ are $\mathrm{D}_{2}$-eGFP neurons (iSPNs; $n=9 ; p<0.05$ ); confirming, in a totally independent way, that iSPNs make stronger inhibitory connections (Plenz, 2003; Taverna et al., 2008; Tecuapetla et al., 2009; Flores-Barrera et al., 2010). According to known anatomy (Kita and Kita, 2001; Mallet et al., 2012), pallidostriatal inhibition would not produce this result.

The present results reinforce the view that the activity of neuron pools from the direct and indirect pathways is continually balanced by feedback inhibition (Carrillo-Reid et al., 2011). 

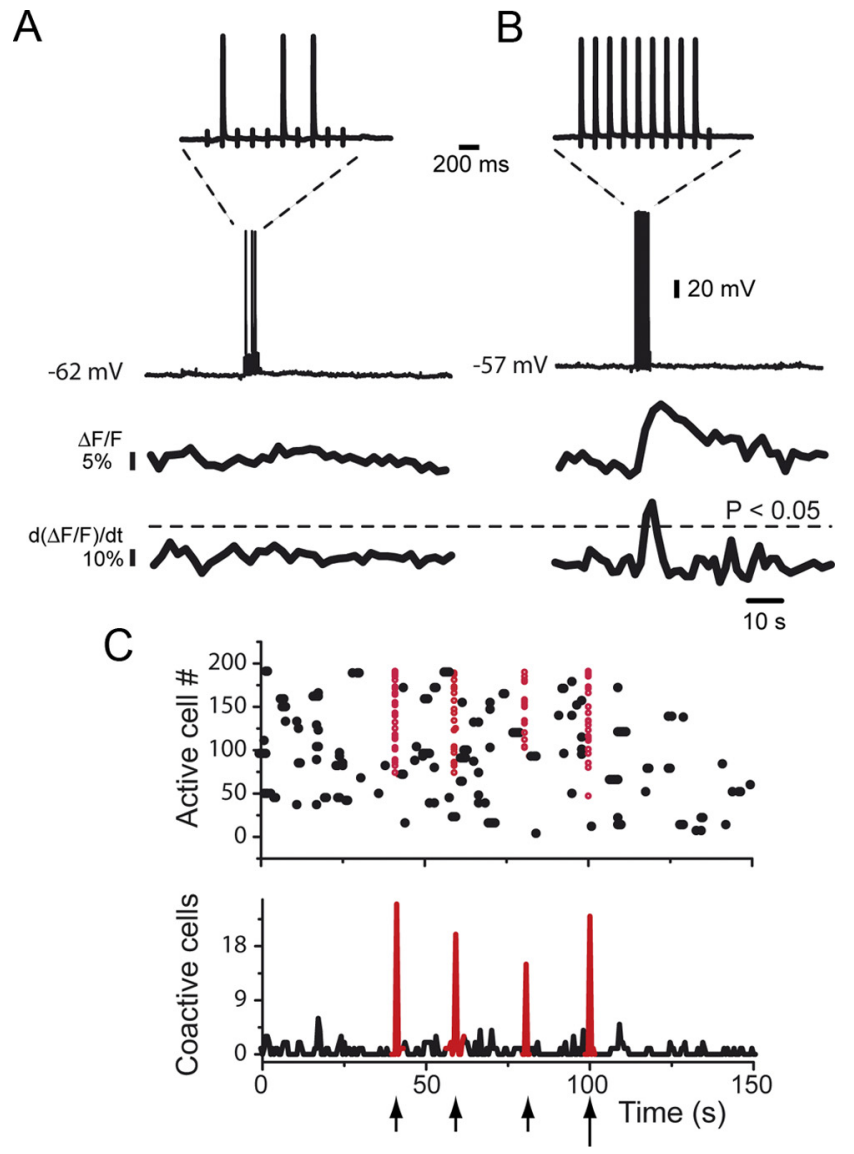

Figure 5. Weakly antidromic invasion of striatal neurons can be amplified. $\boldsymbol{A}$, From top to bottom: first trace shows that the neuron presented did not respond to all antidromic stimuli; second trace shows the same response at a slower time base; third and fourth traces show that infrequent action potentials do not elicit a significant calcium transient (compare with Fig. 4D). $B$, Traces similar to $A$. The same cell was depolarized $5 \mathrm{mV}$ (with DC current) and the strength of stimulation slightly increased: the neuron now responds with action potentials to each antidromic stimulus and exhibits a significant calcium transient, suggesting that probable inhibitory influences for antidromic invasion could be overcome. C, Raster plot (top) and activity histogram (bottom) show that neuronal vectors exhibit less active neurons upon repetitive stimulation (compare with Fig. $4 A$ ), but that the number of active neurons can be recovered after an increase in stimulus strength. Reversal potential of inhibitory responses is $\sim-60 \mathrm{mV}$ (e.g., Flores-Barrera et al., 2009).

\section{Feedback inhibition of neuron pools is disrupted in Parkinsonism}

Experiments in animal models of parkinsonism have shown that DA deprivation impairs the connections among SPNs (Taverna et al., 2008; Tecuapetla et al., 2009). This phenomenon is accompanied by a restriction of striatal microcircuit dynamics where most neurons become sequestered into a dominant network state (Jáidar et al., 2010). At the same time, spontaneous activity is enhanced (Jáidar et al., 2010; López-Huerta et al., 2012) and antikinetic oscillatory discharges become prominent in basal ganglia circuits (Hutchison et al., 2004; Weinberger and Dostrovsky, 2011; Wichmann and Dostrovsky, 2011). To evaluate the impact of feedback inhibition in the striatal microcircuit during pathological states, we used the 6-OHDA rodent model of parkinsonism evaluating both turning behavior (see Materials and Methods) and TH immunocytochemistry. The result of unilateral DA deprivation in a BAC mouse (Fig. 7A) shows the depleted side with eGFP fluorescence (green), whereas the noninjured side exhibits an overlay of eGFP with CY3 (red) used to visualize TH. After DA deprivation, the striatum exhibits spontaneous activity recorded with both electrophysiology (Pomata et al., 2008; López-Huerta et al., 2012) (Fig. 7B) and calcium imaging (Jáidar et al., 2010) (Fig. 7C). Spontaneous neuron vectors (Fig. 7C, top) and corresponding peaks of synchronization (Fig. $7 C$, bottom), never present in control tissue, now become evident (Jáidar et al., 2010). To test the inhibitory connections among SPNs, we added $10 \mu \mathrm{M}$ CNQX plus $50 \mu \mathrm{M}$ APV to abolish parkinsonian spontaneous activity known to be dependent on glutamatergic transmission (Jáidar et al., 2010). After the blockade of excitatory transmission, the DA-depleted striatal microcircuit became almost silent (Fig. 7D), allowing the study of SPNs recruitment after antidromic stimulation. Entrainment of neuron pools could be evoked in DA depleted tissue (but see López-Huerta et al., 2012). However, the number of neurons making up the vectors did not increase significantly after the blockade of GABAergic transmission in these conditions (Fig. 7D; compare with Fig. 5). That is, neuronal recruitment evoked by antidromic stimulation no longer produced significant feedback inhibition within the microcircuit. Indeed, contour maps (Fig. 7E) show very few additional responding neurons, and the number of active cells before and after bicuculline exposure remain constant (Fig. 7F).

\section{Discussion}

Antidromic stimulation of striatal projection neurons activates feedback inhibition

Connections among SPNs, as measured at the microcircuit level, are strong enough to arrest the antidromic firing in an entire neuronal pool. Stimulation within the GPe antidromically activates SPNs inside the striatum as seen with calcium imaging and electrophysiology. Both dSPNs and iSPNs were activated in control conditions. Calcium transients resulting from antidromic action potentials (Guzmán et al., 2003) were observed, allowing the recording of dozens of firing SPNs simultaneously. Activation of SPNs evokes inhibition in neighboring SPNs (Plenz et al., 2003).

Several lines of evidence support that most inhibition recorded in the present experimental conditions is feedback inhibition: (1) Collision tests and calcium imaging demonstrated the antidromic discharge of SPNs. When SPNs fire, they inhibit other SPNs orthodromically (Tunstall et al., 2002; e.g., Czubayko and Plenz, 2002; Koos et al., 2004; Venance et al., 2004; Gustafson et al., 2006; Tecuapetla et al., 2007; Taverna et al., 2008; Tepper et al., 2008; Chuhma et al., 2011). (2) This inhibition was obtained when GPe neurons were eliminated (Guzman et al., 2003). (3) Short-term plasticity between SPNs pairs (Tecuapetla et al., 2007) was different from that obtained from pallidal neurons (Connelly et al., 2010; Aceves et al., 2011; Fan et al., 2012; Miguelez et al., 2012). (4) Inhibition among SPNs responds to both $\mathrm{D}_{1}$ and $\mathrm{D}_{2}$ DA receptor agonists (Guzman et al., 2003; Tecuapetla et al., 2007), whereas pallidal cells only express $D_{2}$-like DA receptors, which have not been observed to act presynaptically within the striatum (Miguelez et al., 2012). (5) Antidromically evoked IPSC amplitude correlates with the recruiting of antidromically activated SPNs: both phenomena depend sigmoidally on stimulus strength. In contrast, pallidal inhibition rises in a step-like manner (Tecuapetla et al., 2005; Baufreton et al., 2009; Aceves et al., 2011). (6) Synapses arising from pools of iSPNs are stronger than those arising from dSPNs as previously shown with paired recordings (Taverna et al., 2008; Tecuapetla et al., 2009) (Fig. 6). (7) Antidromically evoked inhibition decreased after DA deprivation (Fig. 7) (Taverna et al., 2008).

These data strongly suggest that most evoked inhibition in the present conditions is striatal feedback inhibition. Nonetheless, 
ways to increase the probability to record pallidal inhibition do exist (Bargas J, unpublished data; but see: Aceves et al., 2011; Miguelez et al., 2012). Some pallidostriatal axons coexist with the more abundant striatopallidal axons even in thin sagittal slices, and their inhibition cannot be ruled out (Mallet et al., 2012; Miguelez et al., 2012). But pallidostriatal afferents should inhibit SPNs, not make them fire. They should also inhibit striatal interneurons (Gerfen and Surmeier, 2011; Mallet et al., 2012), which then would disinhibit SPNs reinforcing feedback inhibition. Inhibition was cumulative on previous antidromically evoked discharge at a relatively brief time intervals (Fig. 4), a result not consistent with the tens of seconds to recover (70 s) (Atherton et al., 2011) needed by pallidal synapses (Miguelez et al., 2012).

The spatial impact of inhibition after $\mathrm{GABA}_{\mathrm{A}}$-receptor antagonists was revealed by an increase in antidromically recruited SPNs with the same stimulus. A second neuronal pool appeared, intermingled with the first, suggesting that first activated neurons were inhibiting neighboring neurons from the second pool. Disclosed neurons appeared in the same field of view of the first activated neurons. Most neurons disclosed by $\mathrm{GABA}_{\mathrm{A}}$ antagonists appeared within $80 \mu \mathrm{m}$ of their nearest neighbors from the first pool, a distance reported to increase the probability to record pairs of SPNs (Taverna et al., 2004; Tecuapetla et al., 2007). After $\mathrm{GABA}_{\mathrm{A}}$ antagonists, newly recruited neurons were mostly iSPNs in agreement with reported synaptic weights (Taverna et al., 2008): stronger inhibitory actions among iSPNs.

To have a significant impact, pallidal axonal arborizations would have to be present in the field of view $(800 \times 600 \mu \mathrm{m}$ in size; see Materials and Methods), something hard to expect in a $250 \mu \mathrm{m}$ sagittal slice (Kita and Kita, 2001; Mallet et al., 2012). Nonetheless, neurons in the second pool that appeared far away from their local neighbors could very well be inhibited by pallidal axons (Fig. 6). Then, to facilitate the recording of pallidostriatal inhibition in the microcircuit, the use of different techniques as well as different slice orientations (Bargas J, unpublished data), out of the scope of the present report, are needed (Mallet et al., 2012).

\section{Feedback inhibition onto neuronal pools}

Because unitary feedback inhibition has been reported as too weak (Koos et al., 2004; Tepper et al., 2008), we infer that the inhibition we observe at the microcircuit level is not unitary: to arrest neuronal firing, several SPNs must converge onto postsynaptic SPNs (Guzman et al., 2003; Tepper et al., 2004; Chuhma et

$\mathrm{B}$
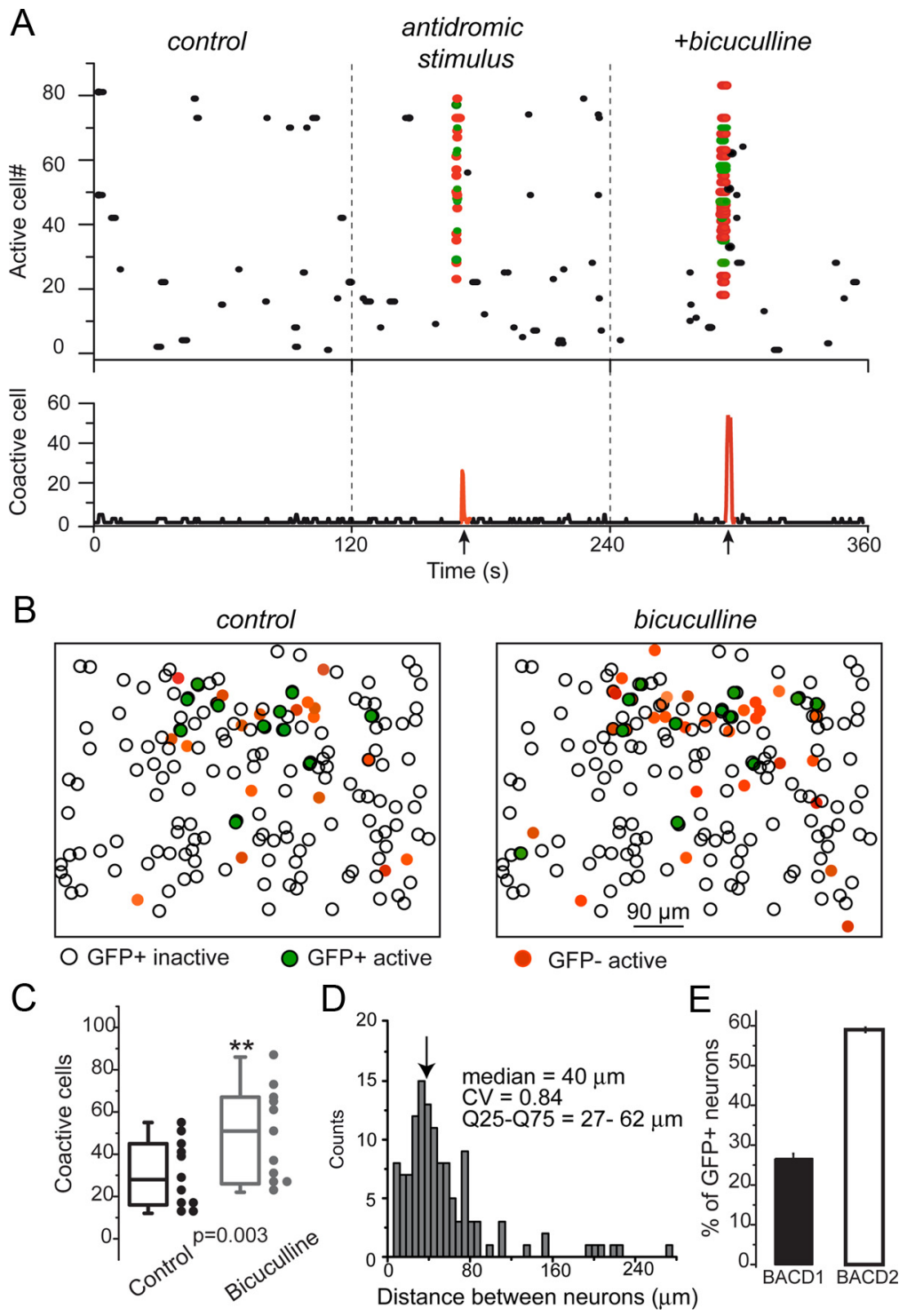

Figure 6. Blockade of GABAergic transmission reveals strong feedback inhibition among SPNs. $\boldsymbol{A}$, Left panel in raster plot, striatal spontaneous activity without stimulus. There is no significant synchronization in this condition. Middle, Peak of synchronization evoked antidromically (arrow; train of 10 stimuli at $20 \mathrm{~Hz}$, each stimulus had $0.2 \mathrm{~ms}$, and $\sim 14 \mu \mathrm{A}, \mathrm{BACD}_{1}$ mouse). Right, When $10 \mu \mathrm{m}$ bicuculline was added to the bath saline, more neurons are recruited by the same stimulus. Activity histogram of the raster plot at bottom denotes that the same stimulus nearly doubles the number of responsive neurons (peak of synchronization), demonstrating that some neurons were actively inhibited during antidromic stimulation. $\boldsymbol{B}$, Contour maps of neurons in the field of view in control conditions and in the presence of bicuculline: empty circles represent unresponsive eGFP ${ }^{+}$neurons; filled green circles, responsive $\mathrm{eGFP}^{+}$neurons; and red symbols, responsive eGFP ${ }^{-}$neurons ( $n=11$ slices using both BAC D1 and D2 mice). C, Box plots illustrate that the number of coactive cells during antidromic stimulation is significantly increased during bicuculline $(10 \mu \mathrm{M})$ or gabazine $(10 \mu \mathrm{M})$ applications. $\boldsymbol{D}$, Distribution of distances between neurons recruited after $\mathrm{GABA}_{\mathrm{A}}$-receptor antagonists and their nearest neighbors active in control conditions ( $n=5$ slices). Most distances are $<80 \mu \mathrm{m}$. $\boldsymbol{E}$, Histogram shows that neurons recruited after $\mathrm{GABA}_{A}$-receptor antagonists are mainly $\mathrm{D}_{2}$-eGFP ${ }^{+}$, suggesting that inhibition from iSPNs is stronger. al., 2011). Ca imaging shows that a pool of presynaptic SPNs is capable of inhibiting another pool of postsynaptic SPNs of similar size. Approximately, if smaller unitary feedback IPSCs (approximate quantal size) amounts to $\sim 10 \mathrm{pA}$ (Salgado et al., 2005; Tecuapetla et al., 2007), then saturating evoked IPSCs of $\sim 150$ pA (Fig. 3C) imply that $\sim 5-15$ presynaptic SPNs converge onto each postsynaptic one (assuming linear addition and unitary connections of 1-3 synapses) (Guzman et al., 2003). Because inhibited SPNs amount to $\sim 30$ (Fig. $3 E$ ), then approximately one-fifth to one-half of the activated (first) pool is presynaptic to the second pool unveiled by $\mathrm{GABA}_{\mathrm{A}}$-receptor antagonists. 


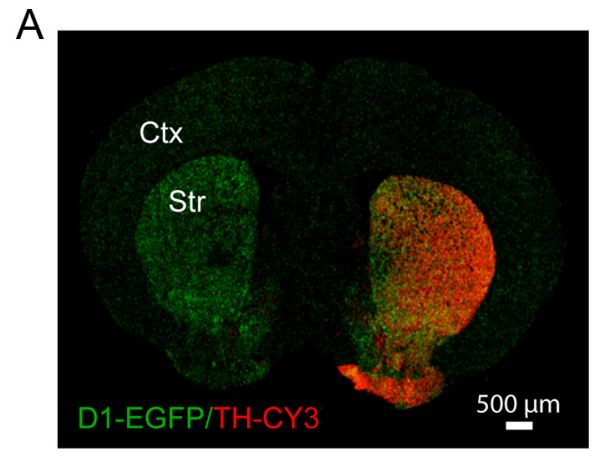

B
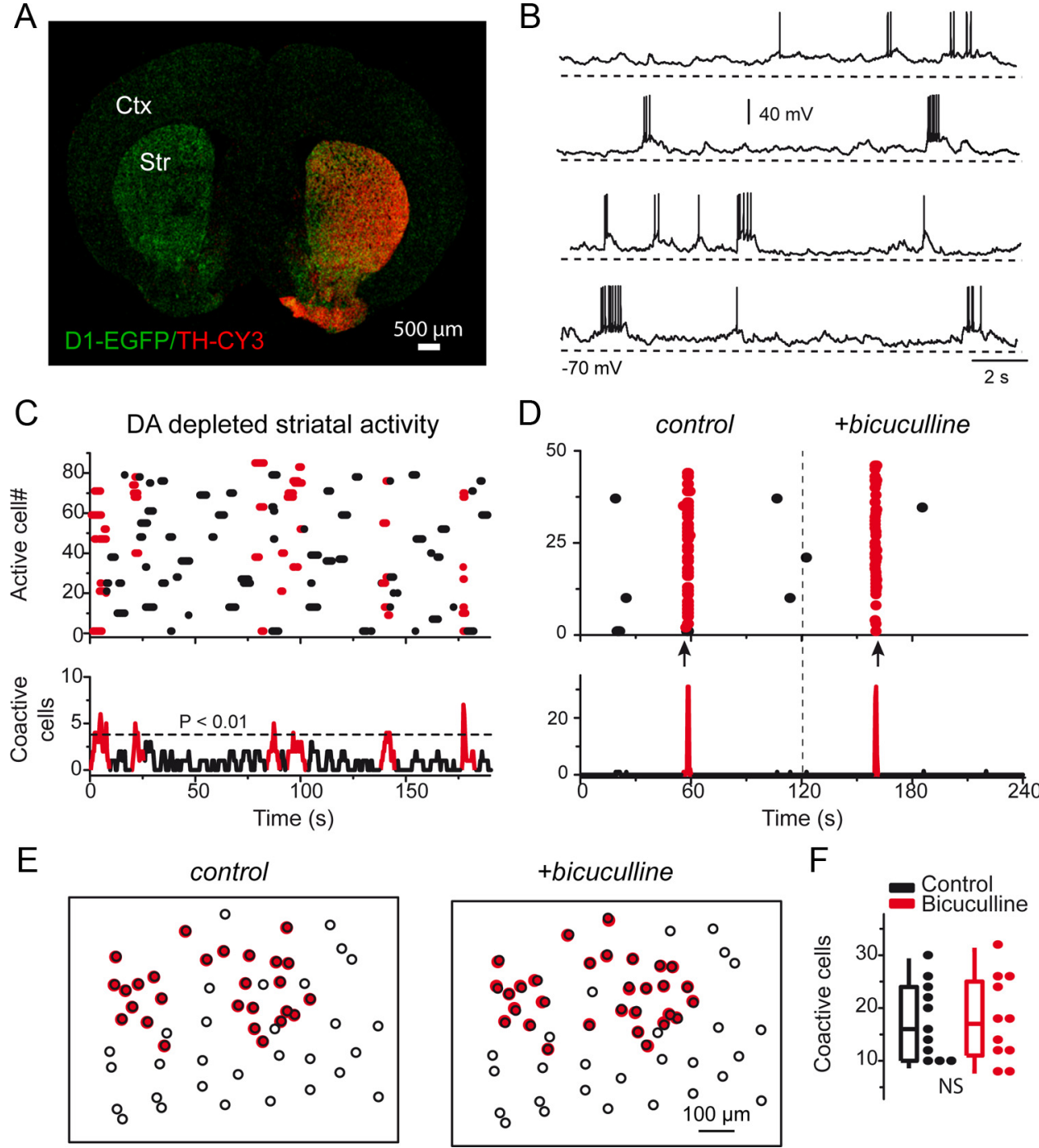

Figure 7. DA deprivation impairs striatal feedback inhibition. $\boldsymbol{A}$, TH immunocytochemistry in 6-OHDA-treated BAC mice. Only eGFP fluorescence is observed in the lesion side (left: green). The nonlesion side is an overlay of eGFP and CY3 (right overlay, red label for TH; see Materials and Methods). $\boldsymbol{B}$, Example of spontaneous firing exhibited by SPNs in the DA-depleted side. Membrane potential is noisy and usually more depolarized than in the controls. C, Top, Raster plot shows that, in contrast to controls (Fig. 5A, left), spontaneous activity in the DA-depleted striatal microcircuit is profuse. Red column vectors illustrate spontaneous events of synchronization. Bottom, Histogram adding up raster plot activity. Spontaneous and statistically significant peaks of synchronization are evident (Jáidar et al., 2010). D, The $10 \mu \mathrm{m}$ CNQX and $50 \mu \mathrm{m}$ APV into the bath saline abolish spontaneous activity (Carrillo-Reid et al., 2008). Top, In these conditions, antidromic stimulation was tested (arrows). Control shows an evoked column vector (red dots). Another evoked column vector is shown during addition of $10 \mu \mathrm{m}$ bicuculline. Bottom, Histogram of overall activity shows that evoked peaks of synchronization contain approximately the same number of coactive neurons before and during bicuculline ( $n=11$ slices). $\boldsymbol{E}$, Representative contour maps of recruited neurons in control conditions (6-OHDA) and during bicuculline exposure. $\boldsymbol{F}$, Box plots summarizing results in a sample of similar experiments: feedback GABAergic transmission appears to be virtually abolished in 6-OHDA-injured animals: cells recruited by antidromic stimulation remain the same before and during bicuculline exposure. Experiments performed in rats and mice (pooled).

Although these experiments show that a convergence of presynaptic SPNs can inhibit the antidromic firing of a pool of postsynaptic SPNs, the numbers obtained above may be different in more physiological conditions because we are testing collateral inhibition against antidromic firing, not against the physiological target: orthodromic firing from the cortex or thalamus (FloresBarrera et al., 2010). Nevertheless, feedback inhibition is known to be lost during DA deprivation (Taverna et al., 2008), and inhibition disclosed here is also lost after unilateral 6-OHDA lesions of the substantia nigra pars compacta, another sign that we evaluated feedback inhibition. In contrast, transmission enhancement has been described for synapses arising from pallidal neurons and striatal interneurons when DA is deprived (Dehorter et al., 2009; Aceves et al., 2011; Jaeger and Kita, 2011; Fan et al., 2012). Connections among SPNs are usually unidirectional (Plenz, 2003; Tepper et al., 2008), suggesting that postsynaptic neurons share their presynaptic neurons (Kawaguchi et al., 1989).

Therefore, each presynaptic SPN may innervate several postsynaptic SPNs, but inputs upon a given SPN need to be convergent to explain inhibition of its firing (Chuhma et al., 2011). That is, efficient feedback inhibition is not neuron to neuron but ensemble to ensemble (Wickens et al., 1991; Beiser et al., 1997; Bar-Gad and Bergman, 2001; Pennartz et al., 2009). Unidirectional connections suggest how an assembly-like temporal sequence may be established following stringent recurrent trajectories (Hebb, 1949; Carrillo-Reid et al., 2009; Ponzi and Wickens, 2010), hard to explain by stochastic processes but easily explained by previously sculpted patterns of synaptic weights (Surmeier et al., 2011). Alternating neuronal ensembles are supported by pools of 30-40 neurons (Carrillo-Reid et al., 2008). Feedback inhibition may be a recovery variable allowing alternation (Ponzi 
and Wickens, 2010; Surmeier et al., 2011). When these connections are disabled, alternation stops, so that neuronal hyperexcitability found in the parkinsonian state falls into a dominant pathological state (Jáidar et al., 2010). Feedback connections as well as interneurons can be modulated by both DA and acetylcholine (e.g., Yan and Surmeier, 1997; Perez-Rosello et al., 2005; Tecuapetla et al., 2007; Carrillo-Reid et al., 2009, 2011; Gerfen and Surmeier, 2011).

\section{Connections among SPNs are not only mutually inhibitory, but they also contribute to assembly dynamics}

Feedback inhibition evoked at certain frequency $(\sim 0.1 \mathrm{~Hz})$ accumulates, so that previously responding cells become inhibited. Strong inhibition from any source onto a pool of neurons may synchronize them (Baufreton et al., 2009), electrical synapses would contribute (Venance et al., 2004) as well as depolarizing GABAergic inhibition in dSPN (Flores-Barrera et al., 2010). Connections of SPNs onto the cholinergic interneurons (Chuhma et al., 2011) would incorporate an intrinsic oscillator to the circuit (Surmeier et al., 2011) that could integrate one or several kinds of interneurons (Bennett et al., 2000; Tepper et al., 2010; English et al., 2011; Goldberg and Reynolds, 2011) to reset or change the activation sequence.

Here, we show that the balance and strength of feedback inhibition between basal ganglia pathways are disrupted after DA deprivation (Taverna et al., 2008). A DA tone and a constant occupation of presynaptic receptors may be necessary to maintain viable connections. Absence of this tone may lead to either decrease or enhancement of synaptic activity in different synapses (Aceves et al., 2011). The present and previous data support that connections among SPNs are not only inhibitory but may contribute to assembly dynamics (Jáidar et al., 2010). When observed at the microcircuit level, inhibition among SPNs is strong enough to arrest the firing in a neuron pool and thus contribute to microcircuit dynamics lost in parkinsonism. The restoration of feedback inhibition in the striatal network may improve striatal function during parkinsonism.

\section{References}

Aceves JJ, Rueda-Orozco PE, Hernández R, Plata V, Ibañez-Sandoval O, Galarraga E, Bargas J (2011) Dopaminergic presynaptic modulation of nigral afferents: its role in the generation of recurrent bursting in substantia nigra pars reticulata neurons. Front Syst Neurosci 5:6. CrossRef Medline

Albin RL, Young AB, Penney JB (1989) The functional anatomy of basal ganglia disorders. Trends Neurosci 12:366-375. CrossRef Medline

Atherton JF, Menard A, Urbain N, Bevan MD (2011) Profound depression of unitary globus pallidus-subthalamic nucleus synaptic transmission during in vivo-like activity. Soc Neurosci Meeting Abstr 78:9.

Bar-Gad I, Bergman H (2001) Stepping out of the box: information processing in the neural networks of the basal ganglia. Curr Opin Neurobiol 11:689-695. CrossRef Medline

Baufreton J, Kirkham E, Atherton JF, Menard A, Magill PJ, Bolam JP, Bevan MD (2009) Sparse but selective and potent synaptic transmission from the globus pallidus to the subthalamic nucleus. J Neurophysiol 102:532545. CrossRef Medline

Beiser DG, Hua SE, Houk JC (1997) Network models of the basal ganglia. Curr Opin Neurobiol 7:185-190. CrossRef Medline

Bennett BD, Callaway JC, Wilson CJ (2000) Intrinsic membrane properties underlying spontaneous tonic firing in neostriatal cholinergic interneurons. J Neurosci 20:8493-8503. Medline

Carrillo-Reid L, Tecuapetla F, Tapia D, Hernández-Cruz A, Galarraga E, Drucker-Colin R, Bargas J (2008) Encoding network states by striatal cell assemblies. J Neurophysiol 99:1435-1450. CrossRef Medline

Carrillo-Reid L, Tecuapetla F, Ibáñez-Sandoval O, Hernández-Cruz A, Galarraga E, Bargas J (2009) Activation of the cholinergic system endows compositional properties to striatal cell assemblies. J Neurophysiol 101: 737-749. CrossRef Medline

Carrillo-Reid L, Hernández-López S, Tapia D, Galarraga E, Bargas J (2011) Dopaminergic modulation of the striatal microcircuit: receptor specific configuration of cell assemblies. J Neurosci 31:14972-14983. CrossRef Medline

Chuhma N, Tanaka KF, Hen R, Rayport S (2011) Functional connectome of the striatal medium spiny neuron. J Neurosci 31:1183-1192. CrossRef Medline

Connelly WM, Schulz JM, Lees G, Reynolds JN (2010) Differential shortterm plasticity at convergent inhibitory synapses to the substantia nigra pars reticulata. J Neurosci 30:14854-14861. CrossRef Medline

Czubayko U, Plenz D (2002) Fast synaptic transmission between striatal spiny projection neurons. Proc Natl Acad Sci U S A 99:15764-15769. CrossRef Medline

Dehorter N, Guigoni C, Lopez C, Hirsch J, Eusebio A, Ben-Ari Y, Hammond C (2009) Dopamine-deprived striatal GABAergic interneurons burst and generate repetitive gigantic IPSCs in medium spiny neurons. J Neurosci 29:7776-7787. CrossRef Medline

DeLong MR (1990) Primate models of movement disorders of basal ganglia origin. Trends Neurosci 13:281-285. CrossRef Medline

English DF, Ibanez-Sandoval O, Stark E, Tecuapetla F, Buzsáki G, Deisseroth K, Tepper JM, Koos T (2012) GABAergic circuits mediate the reinforcement-related signals of striatal cholinergic interneurons. Nat Neurosci 15:123-130. CrossRef Medline

Fan KY, Baufreton J, Surmeier DJ, Chan CS, Bevan MD (2012) Proliferation of external globus pallidus-subthalamic nucleus synapses following degeneration of midbrain dopamine neurons. J Neurosci 32:13718-13728. CrossRef Medline

Fioravante D, Regehr WG (2011) Short-term forms of presynaptic plasticity. Curr Opin Neurobiol 21:269-274. CrossRef Medline

Flores-Barrera E, Laville A, Plata V, Tapia D, Bargas J, Galarraga E (2009) Inhibitory contribution to suprathreshold corticostriatal responses: an experimental and modeling study. Cell Mol Neurobiol 29:719-731. CrossRef Medline

Flores-Barrera E, Vizcarra-Chacón BJ, Tapia D, Bargas J, Galarraga E (2010) Different corticostriatal integration in spiny projection neurons from direct and indirect pathways. Front Syst Neurosci 4:15. CrossRef Medline

Gerfen CR, Surmeier DJ (2011) Modulation of striatal projection systems by dopamine. Annu Rev Neurosci 34:441-466. CrossRef Medline

Gerfen CR, Young WS 3rd (1988) Distribution of striatonigral and striatopallidal peptidergic neurons in both patch and matrix compartments: an in situ hybridization histochemistry and fluorescent retrograde tracing study. Brain Res 460:161-167. CrossRef Medline

Gittis AH, Kreitzer AC (2012) Striatal microcircuitry and movement disorders. Trends Neurosci 35:557-564. CrossRef Medline

Goldberg JA, Reynolds JN (2011) Spontaneous firing and evoked pauses in the tonically active cholinergic interneurons of the striatum. Neurosci 198:27-43. CrossRef Medline

Gustafson N, Gireesh-Dharmaraj E, Czubayko U, Blackwell KT, Plenz D (2006) A comparative voltage and current-clamp analysis of feedback and feedforward synaptic transmission in the striatal microcircuit in vitro. J Neurophysiol 95:737-752. CrossRef Medline

Guzmán JN, Hernández A, Galarraga E, Tapia D, Laville A, Vergara R, Aceves J, Bargas J (2003) Dopaminergic modulation of axon collaterals interconnecting spiny neurons of the rat striatum. J Neurosci 23:8931-8940. Medline

Hebb DO (1949) The organization of behavior: a neuropsychological theory. New York: Wiley.

Hutchison WD, Dostrovsky JO, Walters JR, Courtemanche R, Boraud T, Goldberg J, Brown P (2004) Neuronal oscillations in the basal ganglia and movement disorders: evidence from whole animal and human recordings. J Neurosci 24:9240-9243. CrossRef Medline

Jaeger D, Kita H (2011) Functional connectivity and integrative properties of globus pallidus neurons. Neurosci 198:44-53. CrossRef Medline

Jáidar O, Carrillo-Reid L, Hernández A, Drucker-Colín R, Bargas J, Hernández-Cruz A (2010) Dynamics of the Parkinsonian striatal microcircuit: entrainment into a dominant network state. J Neurosci 30 : 11326-11336. CrossRef Medline

Kawaguchi Y, Wilson CJ, Emson PC (1989) Intracellular recording of identified neostriatal patch and matrix spiny cells in a slice preparation preserving cortical inputs. J Neurophysiol 62:1052-1068. Medline 
Kita H (1993) GABAergic circuits of the striatum. Prog Brain Res 99:51-72. CrossRef Medline

Kita H, Kita T (2001) Number, origins, and chemical types of rat pallidostriatal projection neurons. J Comp Neurol 437:438-448. CrossRef Medline

Koos T, Tepper JM, Wilson CJ (2004) Comparison of IPSCs evoked by spiny and fast-spiking neurons in the neostriatum. J Neurosci 24:79167922. CrossRef Medline

Kravitz AV, Freeze BS, Parker PR, Kay K, Thwin MT, Deisseroth K, Kreitzer AC (2010) Regulation of parkinsonian motor behaviours by optogenetic control of basal ganglia circuitry. Nature 466:622-626. CrossRef Medline

Kravitz AV, Tye LD, Kreitzer AC (2012) Distinct roles for direct and indirect pathway striatal neurons in reinforcement. Nat Neurosci 15:816-818. CrossRef Medline

López-Huerta VG, Blanco-Hernández E, Bargas J, Galarraga E (2012) Presynaptic modulation by somatostatin in the rat neostriatum is altered in a model of parkinsonism. J Neurophysiol 108:1032-1043. CrossRef Medline

Mallet N, Micklem BR, Henny P, Brown MT, Williams C, Bolam JP, Nakamura KC, Magill PJ (2012) Dichotomous organization of the external globus pallidus. Neuron 74:1075-1086. CrossRef Medline

Miguelez C, Morin S, Martinez A, Goillandeau M, Bezard E, Bioulac B, Baufreton J (2012) Altered pallido-pallidal synaptic transmission leads to aberrant firing of globus pallidus neurons in a rat model of Parkinson's disease. J Physiol 590:5861-5875. CrossRef Medline

Obeso JA, Rodriguez-Oroz M, Marin C, Alonso F, Zamarbide I, Lanciego JL, Rodriguez-Diaz M (2004) The origin of motor fluctuations in Parkinson's disease: importance of dopaminergic innervation and basal ganglia circuits. Neurology 62:S17-S30. CrossRef Medline

Pennartz CM, Berke JD, Graybiel AM, Ito R, Lansink CS, van der Meer M, Redish AD, Smith KS, Voorn P (2009) Corticostriatal interactions during learning, memory processing, and decision making. J Neurosci 29: 12831-12838. CrossRef Medline

Perez-Rosello T, Figueroa A, Salgado H, Vilchis C, Tecuapetla F, Guzman JN, Galarraga E, Bargas J (2005) Cholinergic control of firing pattern and neurotransmission in rat neostriatal projection neurons: role of CaV2.1 and CaV2.2 Ca2+ channels. J Neurophysiol 93:2507-2519. CrossRef Medline

Plenz D (2003) When inhibition goes incognito: feedback interaction between spiny projection neurons in striatal function. Trends Neurosci 26: 436-443. CrossRef Medline

Pomata PE, Belluscio MA, Riquelme LA, Murer MG (2008) NMDA receptor gating of information flow through the striatum in vivo. J Neurosci 28:13384-13389. CrossRef Medline

Ponzi A, Wickens J (2010) Sequentially switching cell assemblies in random inhibitory networks of spiking neurons in the striatum. J Neurosci 30: 5894-5911. CrossRef Medline

Salgado H, Tecuapetla F, Perez-Rosello T, Perez-Burgos A, Perez-Garci E,
Galarraga E, Bargas J (2005) A reconfiguration of $\mathrm{Ca}_{\mathrm{V}} 2 \mathrm{Ca}^{2+}$ channels current and its dopaminergic $\mathrm{D}_{2}$ modulation in developing neostriatal neurons. J Neurophysiol 94:3771-3787. CrossRef Medline

Surmeier DJ, Carrillo-Reid L, Bargas J (2011) Dopaminergic modulation of striatal neurons, circuits, and assemblies. Neurosci 198:3-18. CrossRef Medline

Taverna S, van Dongen YC, Groenewegen HJ, Pennartz CM (2004) Direct physiological evidence for synaptic connectivity between medium-sized spiny neurons in rat nucleus accumbens in situ. J Neurophysiol 91:1111-1121. CrossRef Medline

Taverna S, Ilijic E, Surmeier DJ (2008) Recurrent collateral connections of striatal medium spiny neurons are disrupted in models of Parkinson's disease. J Neurosci 28:5504-5512. CrossRef Medline

Tecuapetla F, Carrillo-Reid L, Guzmán JN, Galarraga E, Bargas J (2005) Different inhibitory inputs onto neostriatal projection neurons as revealed by field stimulation. J Neurophysiol 93:1119-1126. CrossRef Medline

Tecuapetla F, Carrillo-Reid L, Bargas J, Galarraga E (2007) Dopaminergic modulation of short term synaptic plasticity at striatal inhibitory synapses. Proc Natl Acad Sci U S A 104:10258-10263. CrossRef Medline

Tecuapetla F, Koós T, Tepper JM, Kabbani N, Yeckel MF (2009) Differential dopaminergic modulation of neostriatal synaptic connections of striatopallidal axon collaterals. J Neurosci 29:8977-8990. CrossRef Medline

Tepper JM, Koós T, Wilson CJ (2004) GABAergic microcircuits in the neostriatum. Trends Neurosci 27:662-669. CrossRef Medline

Tepper JM, Wilson CJ, Koós T (2008) Feedforward and feedback inhibition in neostriatal GABAergic spiny neurons. Brain Res Rev 58:272-281. CrossRef Medline

Tepper JM, Tecuapetla F, Koós T, Ibáñez-Sandoval O (2010) Heterogeneity and diversity of striatal GABAergic interneurons. Front Neuroanat 4:150. CrossRef Medline

Tunstall MJ, Oorschot DE, Kean A, Wickens JR (2002) Inhibitory interactions between spiny projection neurons in the rat striatum. J Neurophysiol 88:1263-1269. Medline

Venance L, Glowinski J, Giaume C (2004) Electrical and chemical transmission between striatal GABAergic output neurones in rat brain slices. J Physiol 559:215-230. CrossRef Medline

Weinberger M, Dostrovsky JO (2011) A basis for the pathological oscillations in basal ganglia: the crucial role of dopamine. Neuroreport 22:151156. CrossRef Medline

Wichmann T, Dostrovsky JO (2011) Pathological basal ganglia activity in movement disorders. Neuroscience 198:232-244. CrossRef Medline

Wickens JR, Alexander ME, Miller R (1991) Two dynamic modes of striatal function under dopaminergic-cholinergic control: simulation and analysis of a model. Synapse 8:1-12. CrossRef Medline

Yan Z, Surmeier DJ (1997) D5 dopamine receptors enhance Zn2+sensitive $G A B A(A)$ currents in striatal cholinergic interneurons through a PKA/PP1 cascade. Neuron 19:1115-1126. CrossRef Medline 